\title{
Biomarkers of diabetic kidney disease
}

\author{
Helen M. Colhoun ${ }^{1} \cdot$ M. Loredana Marcovecchio ${ }^{2}$ \\ Received: 24 October 2017 / Accepted: 3 January 2018 / Published online: 8 March 2018 \\ (C) The Author(s) 2018. This article is an open access publication
}

\begin{abstract}
Diabetic kidney disease (DKD) remains one of the leading causes of reduced lifespan in diabetes. The quest for both prognostic and surrogate endpoint biomarkers for advanced DKD and end-stage renal disease has received major investment and interest in recent years. However, at present no novel biomarkers are in routine use in the clinic or in trials. This review focuses on the current status of prognostic biomarkers. First, we emphasise that albuminuria and eGFR, with other routine clinical data, show at least modest prediction of future renal status if properly used. Indeed, a major limitation of many current biomarker studies is that they do not properly evaluate the marginal increase in prediction on top of these routinely available clinical data. Second, we emphasise that many of the candidate biomarkers for which there are numerous sporadic reports in the literature are tightly correlated with each other. Despite this, few studies have attempted to evaluate a wide range of biomarkers simultaneously to define the most useful among these correlated biomarkers. We also review the potential of high-dimensional panels of lipids, metabolites and proteins to advance the field, and point to some of the analytical and post-analytical challenges of taking initial studies using these and candidate approaches through to actual clinical biomarker use.
\end{abstract}

Keywords Biomarker $\cdot$ Diabetic kidney disease $\cdot$ Epidemiology $\cdot$ Nephropathy $\cdot$ Review

$\begin{array}{ll}\text { Abbreviations } & \\ \text { ACR } & \text { Albumin to creatinine ratio } \\ \text { ADMA } & \text { Asymmetric dimethylarginine } \\ \text { ApoA4 } & \text { Apolipoprotein A4 } \\ \text { B2M } & \beta_{2} \text {-Microglobulin } \\ \text { C1QB } & \text { Complement C1q subcomponent subunit B } \\ \text { CD5L } & \text { CD5 antigen-like } \\ \text { CKD } & \text { Chronic kidney disease } \\ \text { CKD273 } & \text { CKD classifier based on 273 } \\ & \text { urinary peptides } \\ \text { CKD-EPI } & \text { Chronic Kidney Disease } \\ & \text { Epidemiology Collaboration }\end{array}$

Electronic supplementary material The online version of this article (https://doi.org/10.1007/s00125-018-4567-5) contains a slideset of the figures for download, which is available to authorised users.

Helen M. Colhoun

Helen.colhoun@igmm.ed.ac.uk

1 MRC Institute of Genetics \& Molecular Medicine, The University of Edinburgh, Western General Hospital, Crewe Road,

Edinburgh EH4 2XU, UK

2 Department of Paediatrics, University of Cambridge, Cambridge, UK
CVD Cardiovascular disease

DKD Diabetic kidney disease

ESRD End-stage renal disease

FGF Fibroblast growth factor

KIM-1 Kidney injury molecule-1

L-FABP Liver-type fatty acid-binding protein

MCP-1 Monocyte chemoattractant protein-1

MDRD Modification of Diet in Renal Disease

miRNA MicroRNA

MR-proADM Mid-regional fragment of proadrenomedullin

NGAL Neutrophil gelatinase-associated lipocalin

NT-proNBP N-terminal pro-B-type natriuretic peptide

PRIORITY Proteomic Prediction and Renin

Angiotensin Aldosterone System Inhibition Prevention Of Early

Diabetic nephRopathy In TYpe 2 Diabetic

Patients With Normoalbuminuria

SBP Systolic BP

SDMA Symmetric dimethylarginine

SUMMIT SUrrogate markers for Micro- and

Macro-vascular hard endpoints for Innovative diabetes Tools 
SYSKID Systems biology towards novel chronic kidney disease diagnosis and treatment

TNFR TNF receptor

VEGF Vascular endothelial growth factor

\section{Introduction}

Diabetic kidney disease (DKD) and its most severe manifestation, end-stage renal disease (ESRD), remains one of the leading causes of reduced lifespan in people with diabetes [1]. Even early stages of DKD confer a substantial increase in the risk of cardiovascular disease (CVD) $[1,2]$, so the therapeutic goal should be to prevent these earlier stages, not just ESRD. However, there has been an impasse in the development of drugs to reverse DKD, with many Phase 3 clinical trial failures [3]. The current hard endpoints for the licencing of drugs for chronic kidney disease (CKD) or DKD approved by most authorities, including the US Food and Drug Administration, are a doubling of serum creatinine or the onset of ESRD or renal death. Some of the trial failures are due to insufficient power, with low overall rates of progression to these hard endpoints during the typical trial duration of 37 years. As a result, there is increasing interest in the development of prognostic or predictive biomarkers to allow for risk stratification into clinical trials, as well as eventually for targeting preventive therapy. There is also interest in the development of biomarkers of drug response that are surrogates for these harder endpoints. Here we review some of the larger studies published in the last 5 years on prognostic or predictive biomarkers for DKD. Our emphasis is on illustrating some key aspects of the approaches being used recently and what further improvements are needed, rather than systematically reviewing every sporadic biomarker report.

\section{Biomarkers currently in use}

It is well established that the best predictor of future ESRD is the current GFR and past GFR trajectory [4]. Thus, GFR is the most common prognostic biomarker being used for predicting ESRD in both clinical practice and in trials. The Chronic Kidney Disease Epidemiology Collaboration (CKD-EPI) and Modification of Diet in Renal Disease (MDRD) equations, both based on serum creatinine, are commonly used to estimate GFR. The difference in accuracy for staging between CKD-EPI and MDRD is slight, with $69 \%$ vs $65 \%$ overall accuracy for given stages being found in one study [5]. Serum cystatin C-based eGFR has been proposed as advantageous since, unlike creatinine, it is not related to muscle mass. Equations based on cystatin $\mathrm{C}$ overestimated directly measured GFR, while equations based on serum creatinine underestimated GFR in a large study [6]. Others have found that creatinine agrees more closely than cystatin $\mathrm{C}$ with directly measured GFR [7]. In those with and without diabetes, cystatin C predicts CVD mortality and ESRD better than eGFR does [8,9]. However, this may be because factors other than renal function that affect ESRD risk, including diabetes, might also affect serum cystatin $\mathrm{C}$ levels, rather than because cystatin C-based eGFR is more accurately measuring GFR itself [10].

Albuminuria strongly predicts progression of DKD but it lacks specificity and sensitivity for ESRD and progressive decline in eGFR. In type 2 diabetes a large proportion of those who have renal disease progression are normoalbuminuric $[11,12]$. It has been shown that the coexistence of albuminuria makes DKD rather than non-diabetic CKD more likely in people with type 2 diabetes [13]. However, even in type 1 diabetes, where non-diabetic CKD is much less common, albuminuria was reported to have a poor positive predictive value for DKD as only about a third of those with microalbuminuria had progressive renal function decline [14]. Albumin excretion also had low sensitivity, as only about half of those with progressive renal function decline were albuminuric [14]. Clearly, in evaluating the predictive performance of novel biomarkers, investigators should adjust for baseline eGFR and albuminuria. Historical eGFR data are not always routinely available. Nonetheless, it is important where possible to evaluate whether biomarkers improve prediction on top of historical eGFR.

\section{Clinical predictors of DKD in type 1 and type 2 diabetes}

Apart from albuminuria and eGFR, other risk factors routinely captured in clinical records can predict GFR decline. These have been systematically well reviewed elsewhere [15]. In brief, established clinical risk factors include age, diabetes duration, $\mathrm{HbA}_{1 \mathrm{c}}$, systolic $\mathrm{BP}$ (SBP), albuminuria, prior eGFR and retinopathy status. However, there have been relatively few attempts to build and validate predictive equations using clinical data that would form the basis for evaluating the marginal improvement in prediction with biomarkers [16-18]. Those that have attempted this reported C statistics for ESRD or renal failure death or prediction of incident albuminuria in the range $0.85-0.90$ in type 2 diabetes $[17,18]$. In the Joslin cohorts with type 1 diabetes, eGFR slope, albumin to creatinine ratio (ACR) and $\mathrm{HbA}_{1 \mathrm{c}}$ had a $\mathrm{C}$ statistic (not cross-validated) for ESRD of 0.80 [19-21]. In the FinnDiane cohort the best model had a $\mathrm{C}$ statistic of 0.67 for ESRD [22]. In the Steno Diabetes Center cohort, $\mathrm{HbA}_{1 \mathrm{c}}$, albuminuria, haemoglobin, SBP, baseline eGFR, smoking, and lowdensity lipoprotein/high-density lipoprotein ratio explained $18-25 \%$ of the variability in decline [23]. In the 
EURODIAB cohort predictive models for albuminuria included $\mathrm{HbA}_{1 \mathrm{c}}$, AER, waist-to-hip ratio, BMI and ever smoking with a non-cross-validated $C$ statistic of 0.71 [24].

In summary, most studies have reported at least modest $\mathrm{C}$ statistics for models that contain clinical risk factors beyond eGFR, albuminuria status and age for renal outcomes in type 1 and 2 diabetes. However, despite this, very few biomarker studies have evaluated the marginal improvement in prediction beyond such factors. In the SUrrogate markers for Microand Macro-vascular hard endpoints for Innovative diabetes Tools (SUMMIT) study, for example, while forward selection of biomarkers on top of a limited set of clinical covariates selected a panel of 14 biomarkers as predictive, increasing the $\mathrm{C}$ statistic from 0.71 to 0.89 , a more extensive clinical risk factor model already had a $\mathrm{C}$ statistic of 0.79 and a panel of only seven biomarkers showed an improvement in prediction beyond this [25].

\section{Novel biomarker studies}

Ideally, we seek predictive or prognostic biomarkers of the hard endpoint demanded by drug regulatory agencies (i.e. doubling of serum creatinine or the onset of ESRD or renal death). In practice, since many cohorts do not have the necessary length of follow-up or numbers of incident hard endpoints, many studies have sought biomarkers of intermediate phenotypes such as incident albuminuria, DKD stage 3 or eGFR slopes above a certain threshold (Table 1).

\section{Studies testing single biomarkers or small sets of biomarkers}

Most biomarker reports in the literature are of single candidate biomarkers or small sets of candidate biomarkers that may be assayed in single assays, usually ELISAs, or on multiplexed platforms, such as the Myriad RBM KidneyMAP panel (https://myriadrbm.com/, accessed 17 October 2017). Until recently, most of these studies have taken as their starting point molecules identified from in vitro studies, cell-based studies or animal models. For example, animal models identified kidney injury molecule-1 (KIM-1) [26] and neutrophil gelatinase-associated lipocalin (NGAL) [27]. Candidates studied to date probe pathways thought causal in DKD, such as inflammation, glycation or glycosylation, or endothelial dysfunction. Others focus on glomerular features, such as glycocalyx abnormalities, extracellular matrix deposition, podocyte damage or glomerular fibrosis. Others focus on acute or chronic proximal or distal tubular dysfunction (Fig. 1).

As detailed in Table 1, among these studies of single or few biomarkers, some of the most frequently reported associations with DKD-relevant phenotypes are for biomarkers of inflammation and fibrosis pathways, such as soluble TNF receptors 1 and
2 (sTNFR1 and sTNFR2) [28-33], fibroblast growth factors 21 and 23 (FGF21, FGF23) [25, 34-41] and pigment epitheliumderived factor (PEDF) [42]. Positive associations have also been found for biomarkers of endothelial dysfunction, including midregional fragment of proadrenomedullin (MR-proADM) [43], and cardiac injury, including N-terminal pro-B-type natriuretic peptide (NT-proBNP) [43]. Copeptin, a surrogate marker for arginine vasopressin, was associated with albuminuria progression and incident ESRD independently of baseline eGFR in four studies [44-47]. Proximal tubular proteins, such as urinary KIM-1, NGAL [48-50] and liver-type fatty acid-binding protein (L-FABP) [51-53] have been associated with a faster decline in eGFR [48]. The data are most consistent for KIM-1, a protein expressed on the apical membrane of renal proximal tubule cells, with urinary concentrations rising in response to acute renal injury [49, 54-56]. Urinary and blood levels of KIM-1 increased across CKD stages and were associated with eGFR slopes and progression to ESRD during follow-up in some studies $[57,58]$, but it has not always been a strong independent predictor of progression $[59,60]$. There are reports of its association with regression of microalbuminuria in type 1 diabetes [61]. That these associations could reflect a causal role for KIM1 was suggested by an analysis of the FinnDiane cohort with type 1 diabetes [62]. In this analysis, KIM-1 did not predict progression to ESRD independently of AER. However, using a Mendelian randomisation approach, based on genome-wide association study data for the KIM-1 gene, an inverse association of increased KIM-1 levels with lower eGFR emerged, suggesting a causal link with renal function.

\section{Panels of candidate biomarkers}

Each of the above biomarkers have some evidence supporting their prediction of renal function decline or other DKD-related phenotypes. However, although they have been investigated as reflecting specific pathways or processes, in reality there are very strong correlations between these biomarkers, even between different pathways. Figure 2 shows the correlation matrix for some of these from the SUMMIT study [25]. Yet, relatively few studies have assayed many of these candidates together to allow the marginal gain in prediction with each additional biomarker to be evaluated. Of those that have, some used a hybrid of discovery and candidate approaches harnessing bioinformatics and systems biology modelling techniques [63]. So, for example, in the SUMMIT study [25], we conducted both data mining and literature review to arrive at sets of candidates that several pathophysiological processes considered relevant for DKD. We assayed these but also a larger set of biomarkers (207 in total) that were already multiplexed with these candidates in the most efficient analysis platforms that were Luminex and mass spectrometry-based. Altogether, 30 biomarkers had highly significant evidence of association with renal function decline when examined singly 


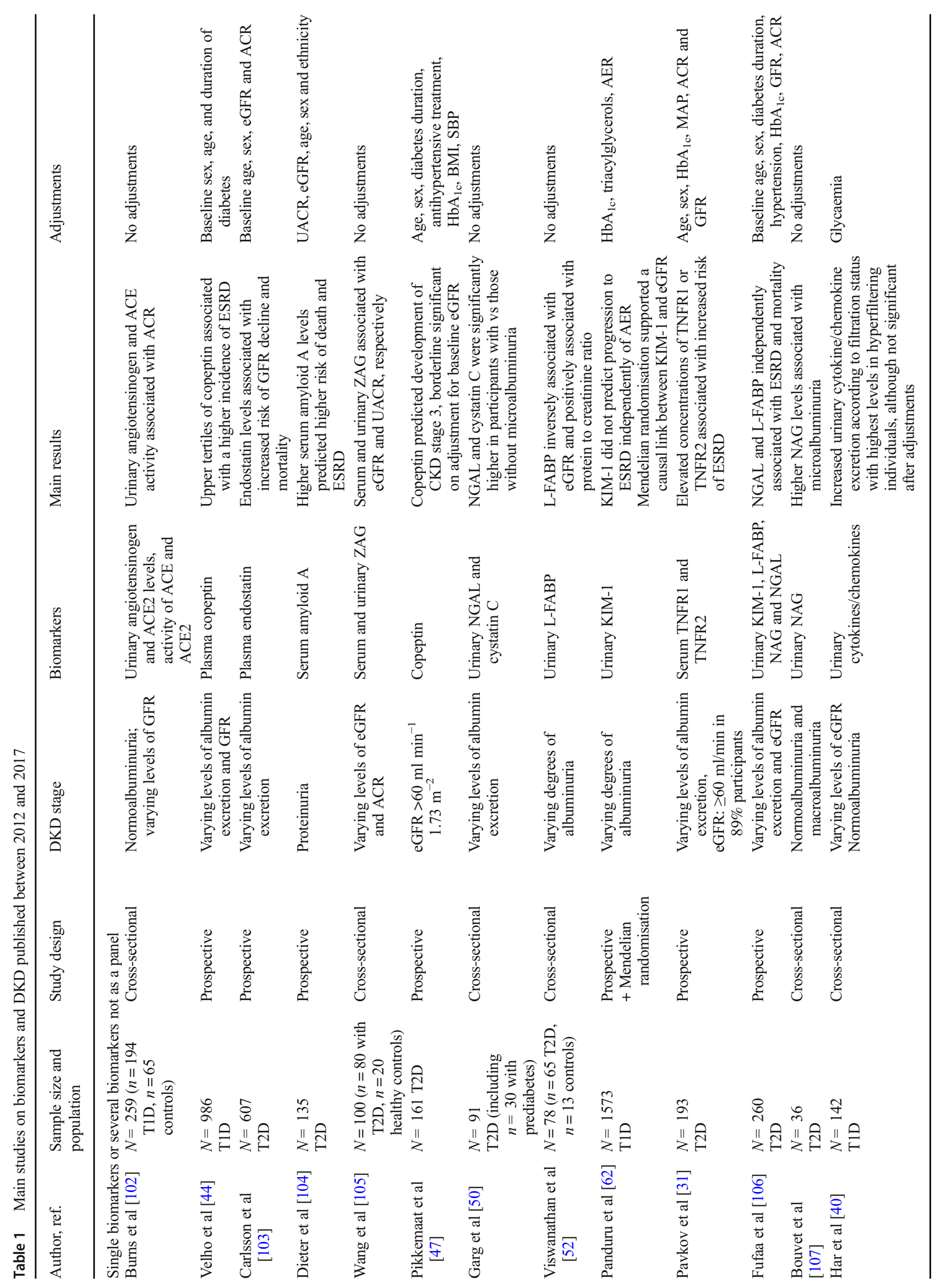




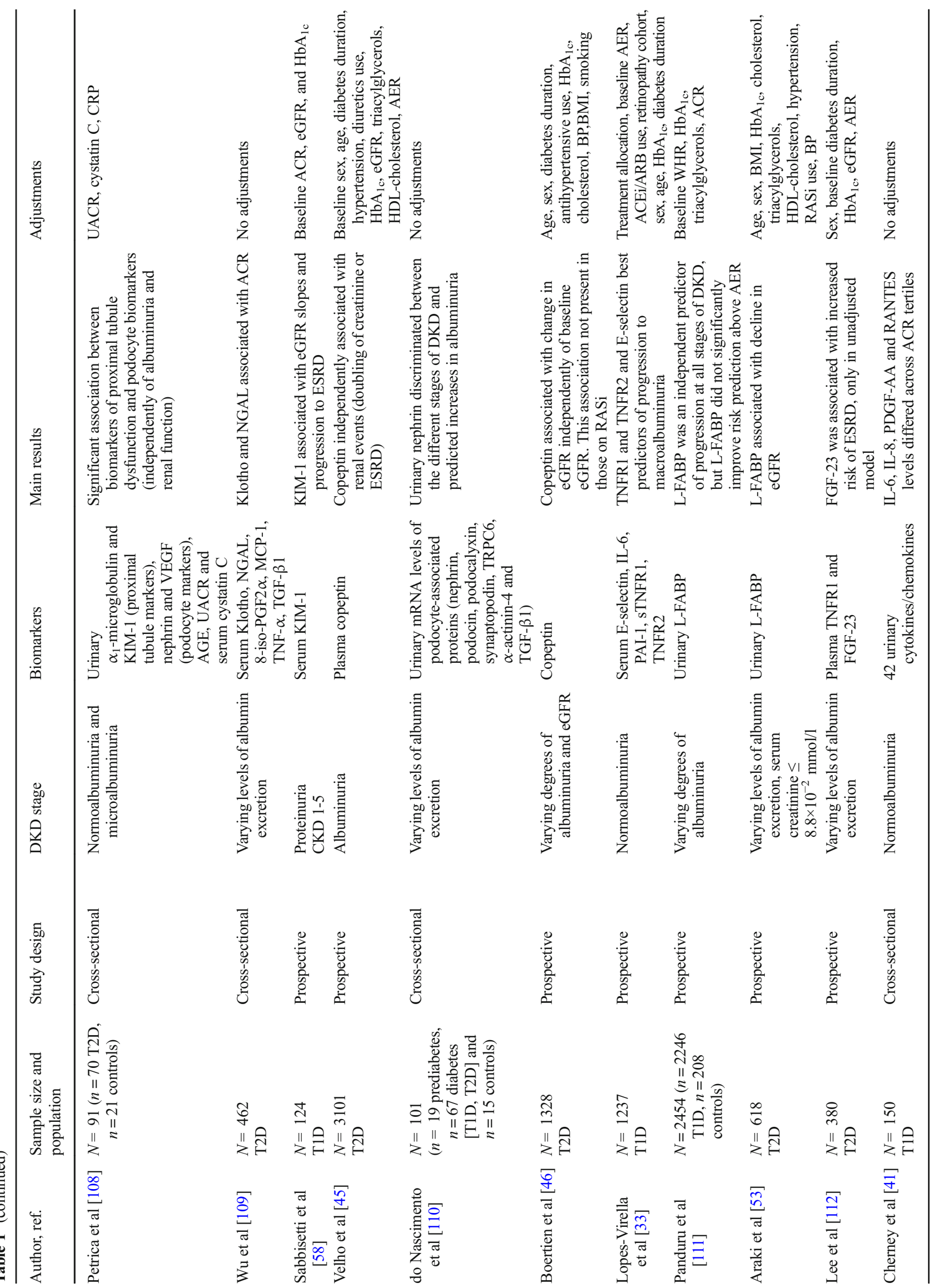




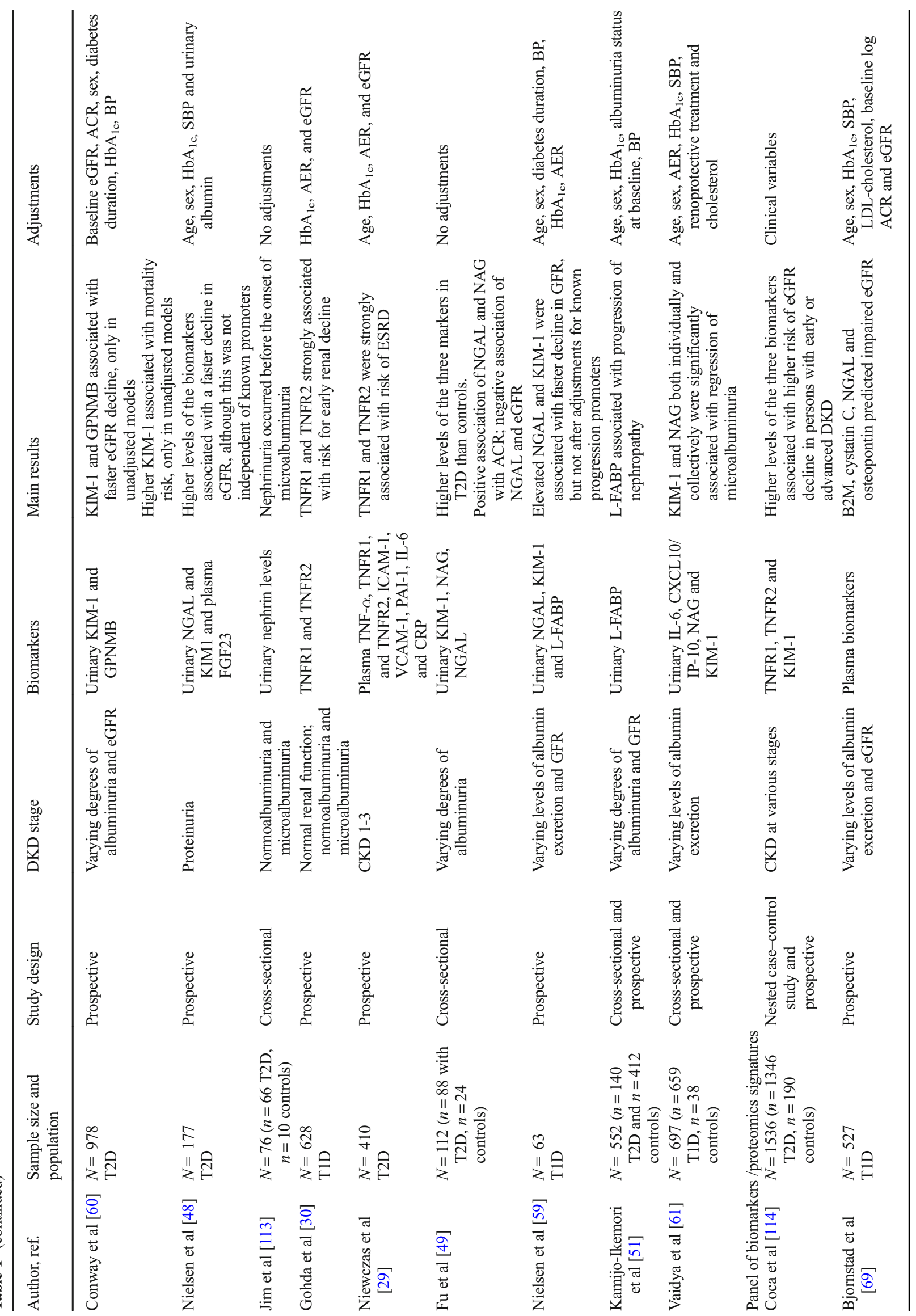




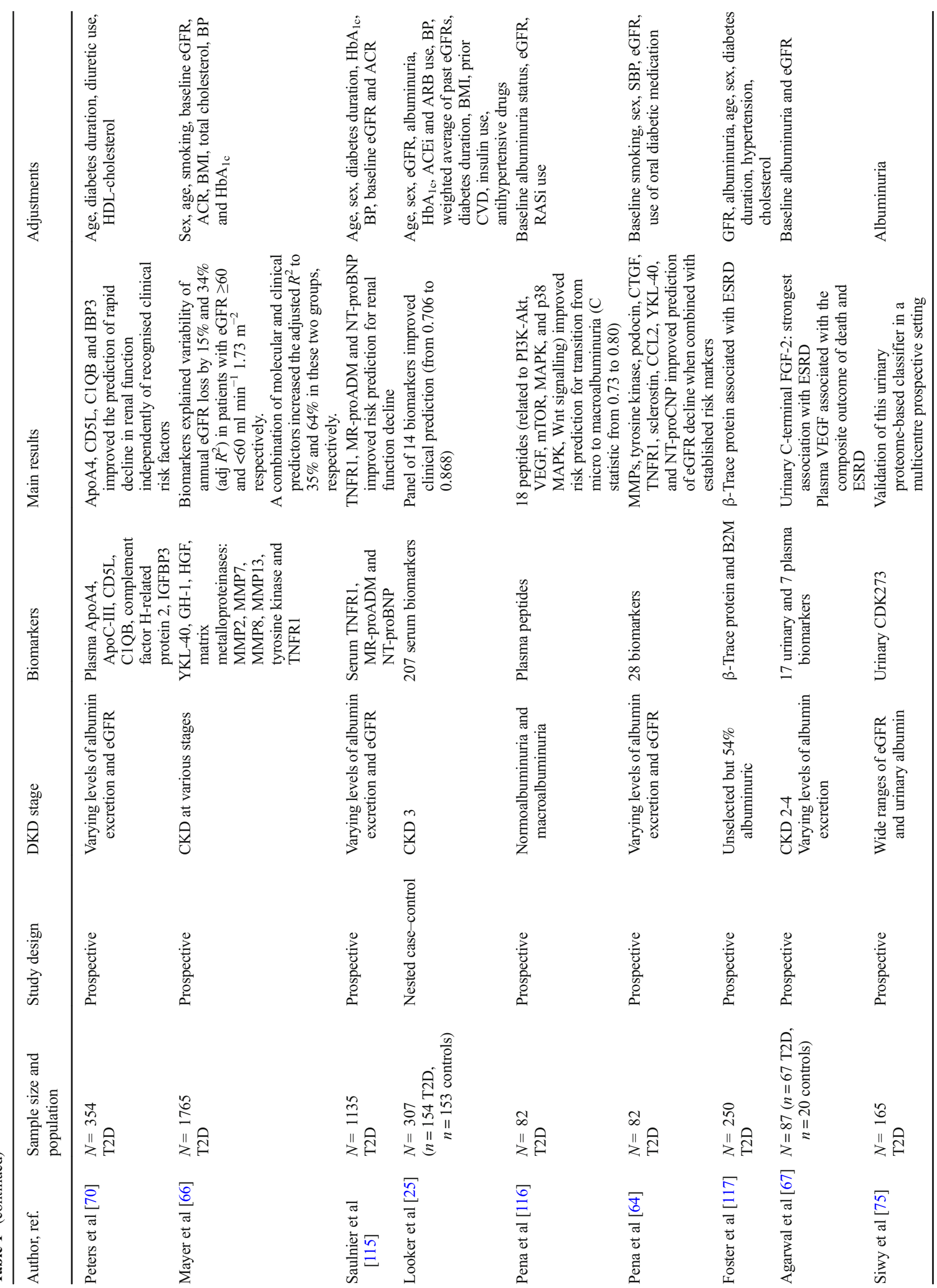




\begin{tabular}{|c|c|c|c|c|c|c|c|c|c|c|c|}
\hline & 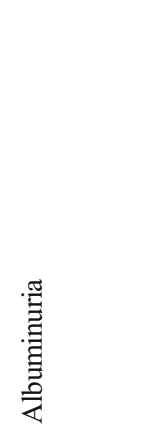 & 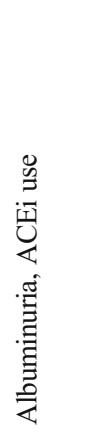 & 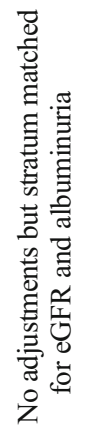 & 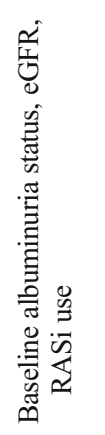 & $\begin{array}{l}\text { 兽 } \\
\text { 兽 } \\
\text { 严 }\end{array}$ & 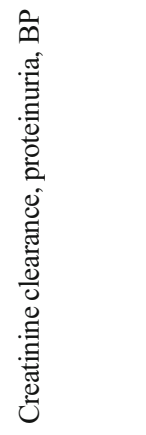 & 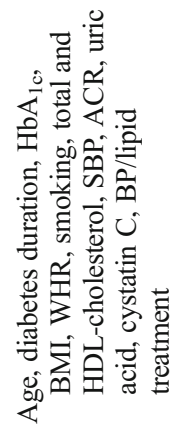 & 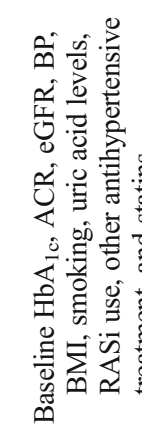 & 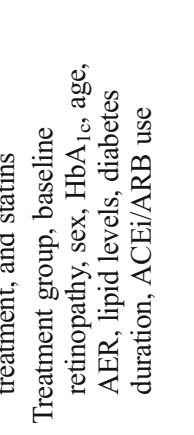 & 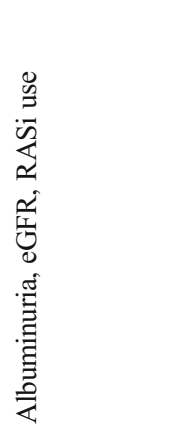 & 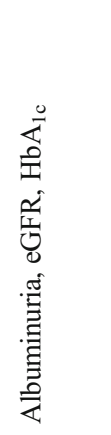 \\
\hline & 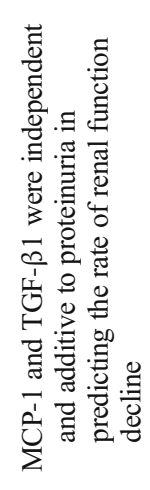 & 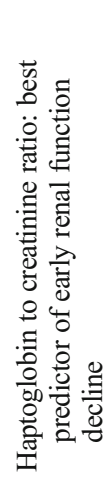 & 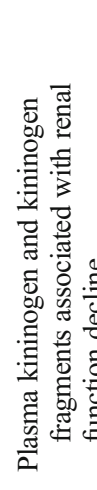 & 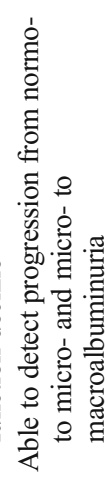 & 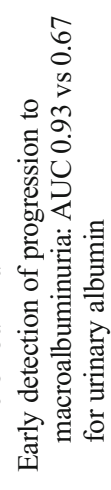 & 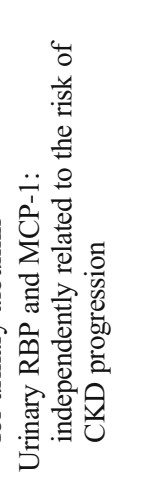 & 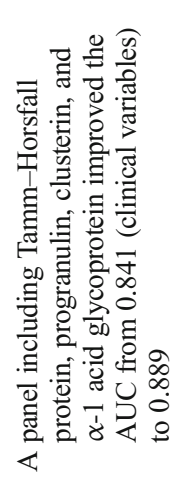 & 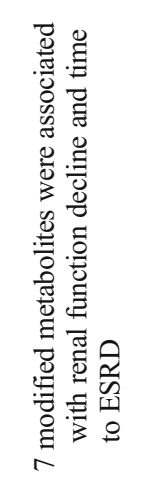 & 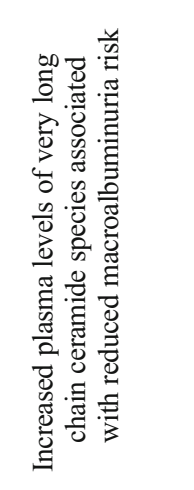 & 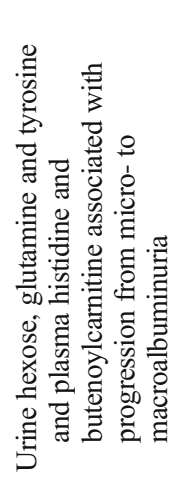 & 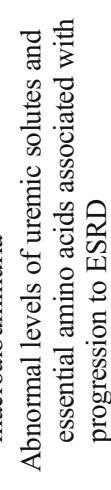 \\
\hline & 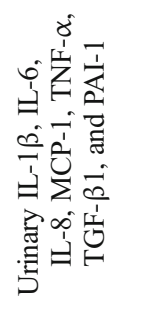 & 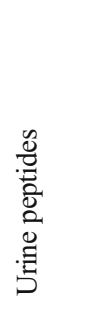 & 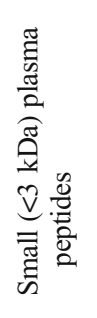 & 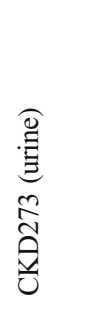 & 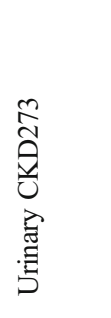 & 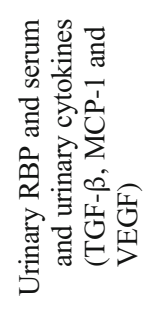 & 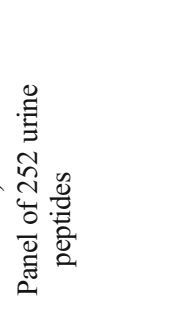 & 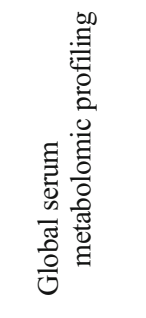 & 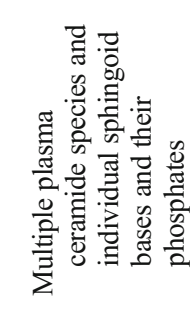 & 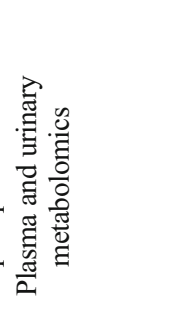 & 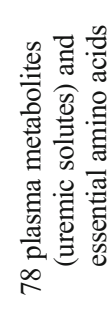 \\
\hline 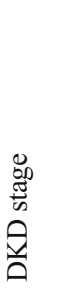 & 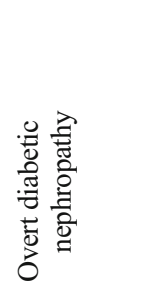 & 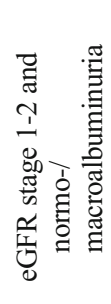 & 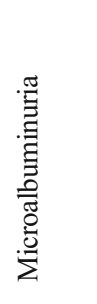 & 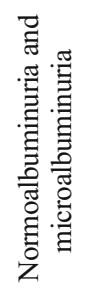 & 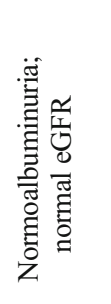 & 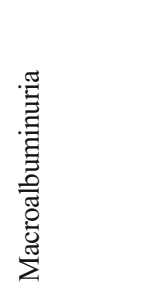 & 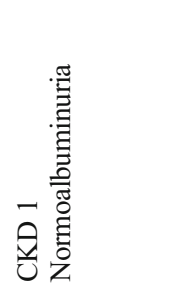 & 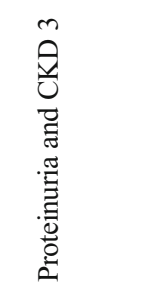 & 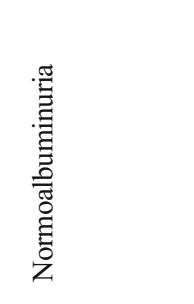 & 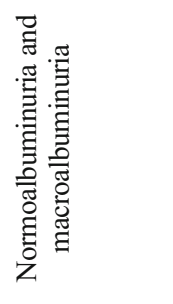 & $\frac{n}{\theta}$ \\
\hline 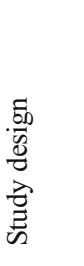 & 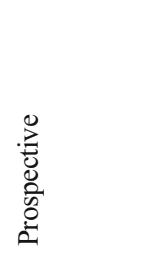 & 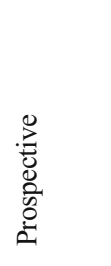 & 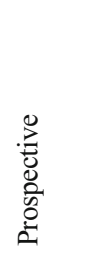 & 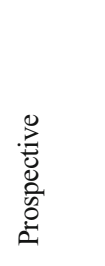 & 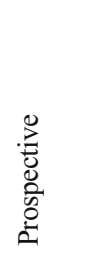 & 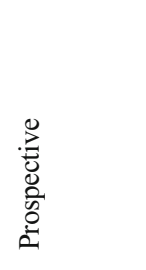 & 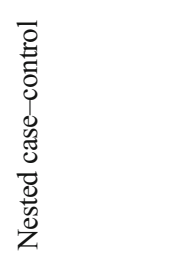 & 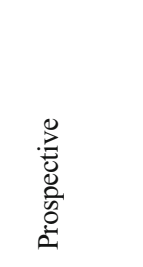 & 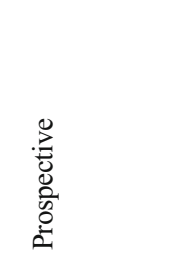 & 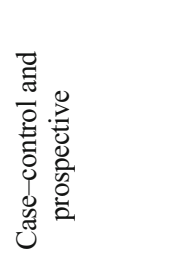 & 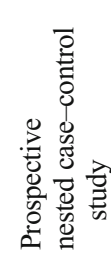 \\
\hline 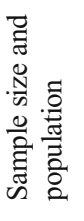 & 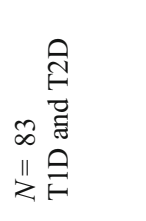 & $\begin{array}{l}\stackrel{+}{N} \\
\text { "I } \\
z\end{array}$ & 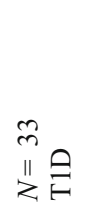 & $\begin{array}{l}\infty \\
\infty \\
z^{\prime \prime}\end{array}$ & 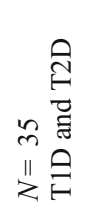 & $\begin{array}{l}\stackrel{n}{n} \\
z_{z}\end{array}$ & \begin{tabular}{l}
\multirow{2}{z}{} \\
+ \\
$\| 1$ \\
$z$
\end{tabular} & 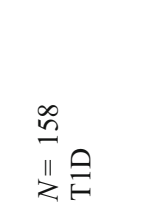 & $\begin{array}{l}\hat{a} \\
\| \\
\stackrel{a}{\|}\end{array}$ & $\begin{array}{l}\stackrel{2}{\|} \\
z\end{array}$ & 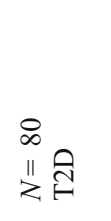 \\
\hline 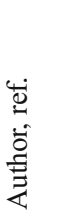 & 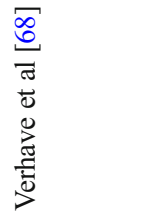 & 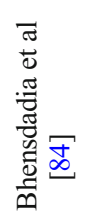 & 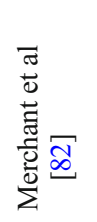 & 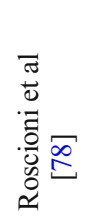 & 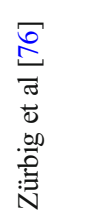 & 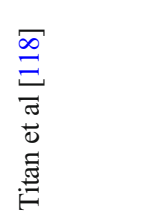 & 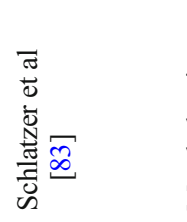 & 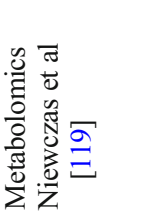 & 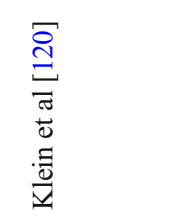 & 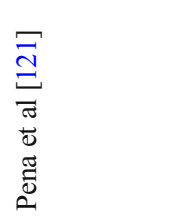 & 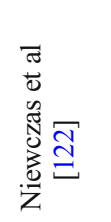 \\
\hline
\end{tabular}




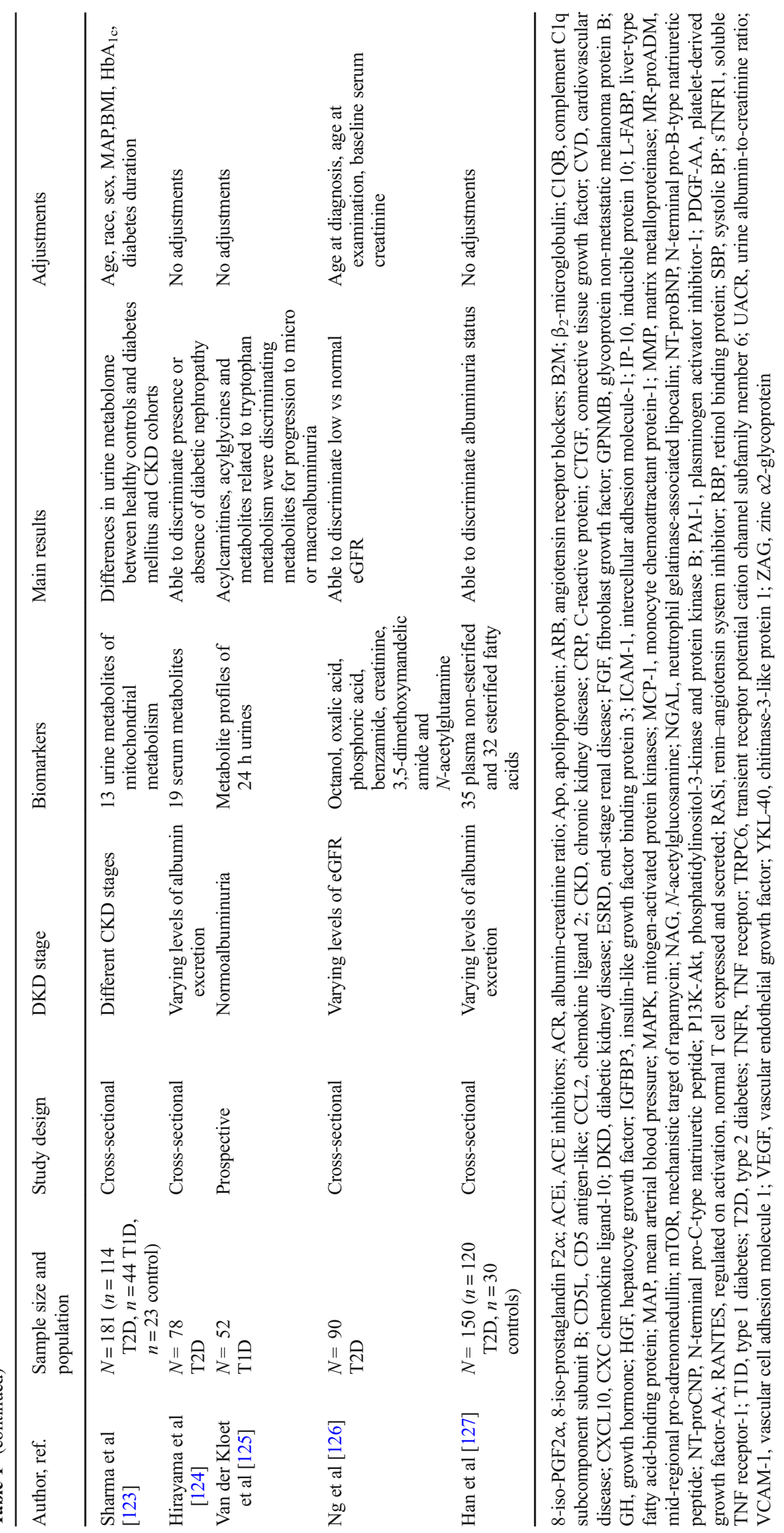




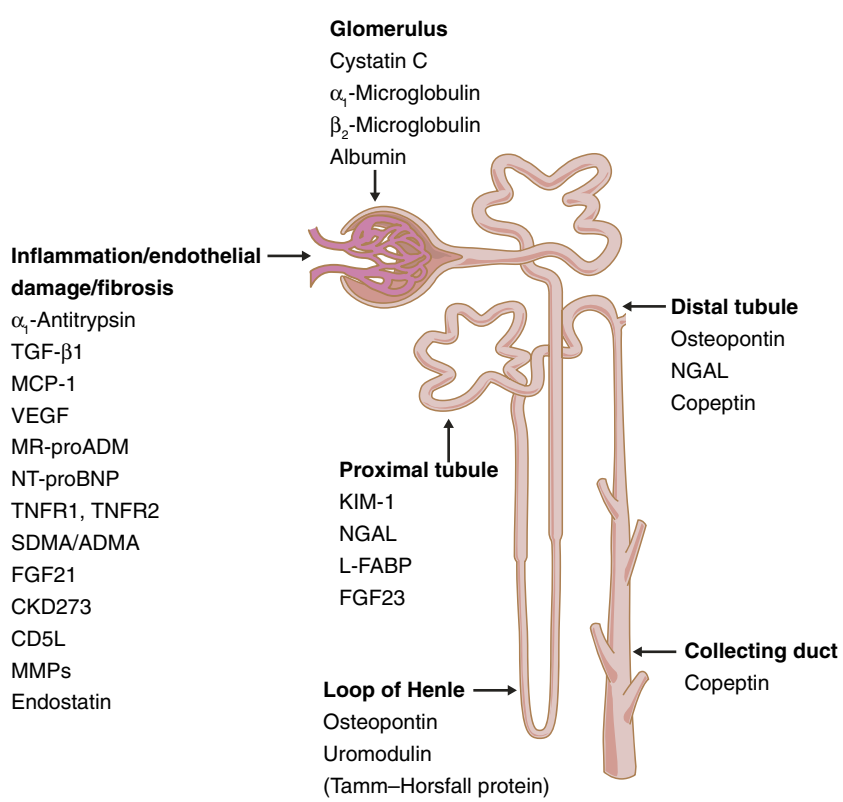

Fig. 1 Presumed site of origin of commonly associated biomarkers predictive of DKD. MMPs, matrix metalloproteases. This figure is available as part of a downloadable slideset

and adjusted for historical and baseline eGFR, albuminuria and other covariates. In forward selection, 14 biomarkers were selected adjusting for this basic set of covariates (Table 1). On top of a more extensive set of covariates, seven biomarkers were selected: KIM-1, symmetric dimethylarginine/asymmetric dimethylarginine (SDMA/ADMA) ratio, $\beta_{2}$-microglobulin (B2M), $\alpha 1$-antitrypsin, C16-acylcarnitine, FGF-21 and uracil.

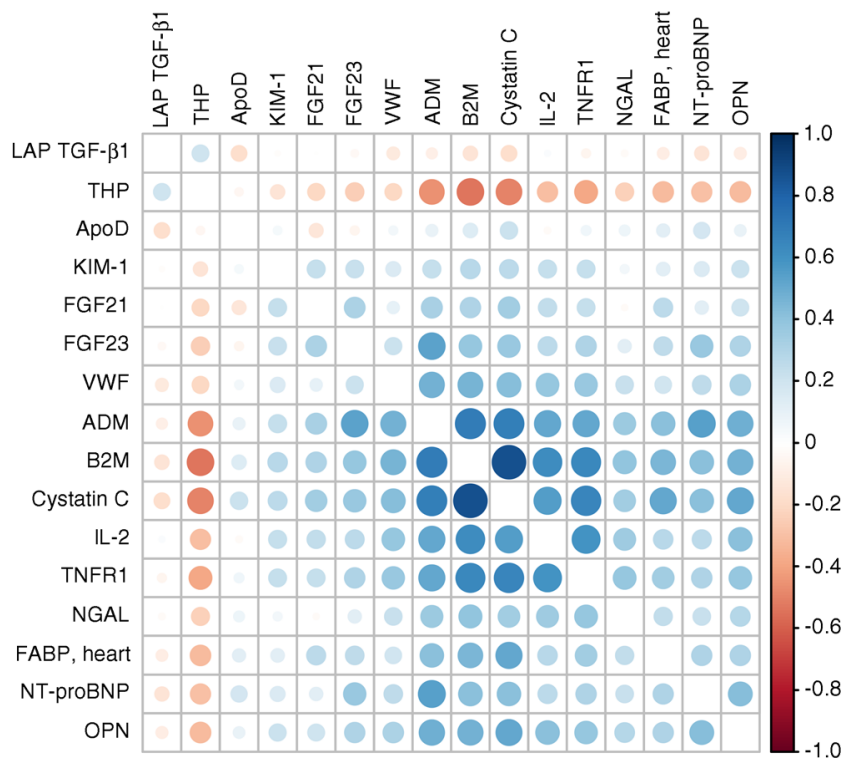

Fig. 2 Correlation matrix of biomarker measures in the SUMMIT project (www.imi-summit.eu/) showing there is high correlation between biomarkers that are of interest because of different pathway involvement. ADM, adrenomedullin; FABP, fatty acid-binding protein; LAP TGF- $\beta 1$, latency-associated-peptide; OPN, osteopontin; THP, Tamm-Horsfall urinary protein; VWF, von Willebrand factor. This figure is available as part of a downloadable slideset
Other such approaches are detailed in Table 1. Of particular note, the Systems biology towards novel chronic kidney disease diagnosis and treatment (SYSKID) consortium used data mining and de novo omics profiling to construct a molecular process model representation of CKD in diabetes [64], choosing ultimately to measure 13 candidates that represented the four largest processes of the model [65]. The panel that gave an increase in prediction of renal disease progression was then reported (C statistic increased from 0.835 to 0.896 ). In a recent validation study of nine of the biomarkers, the investigators reported that the panel was useful in prediction based on an increase in the adjusted $r^{2}$ for the prediction model for eGFR progression from $29 \%$ and $56 \%$ for those with a baseline eGFR above and below $60 \mathrm{ml} \min 1.73 \mathrm{~m}^{-2}$, respectively, to $35 \%$ and $64 \%$, respectively, for the biomarker panel on top of clinical variables [66].

In a study exploring 17 candidate urinary and seven plasma biomarkers in 67 participants with type 2 diabetes, Agarwal et al [67] found that urinary C-terminal FGF-2 showed the strongest association with ESRD, whereas plasma vascular endothelial growth factor (VEGF) was associated with the composite outcome of death and ESRD. The analysis was adjusted for baseline eGFR only and ACR. Of a panel of seven candidates, Verhave et al found that urinary monocyte chemoattractant protein-1 (MCP-1) and TGF- $\beta 1$ predicted renal function decline independently of albuminuria. Adjustment for baseline eGFR was not made as it surprisingly did not predict decline in univariate testing [68]. In the Coronary Artery Calcification in Type 1 Diabetes (CACTI) study using Kidney Injury Panels 3 and 5, (Meso Scale Diagnostics, www.mesoscale.com/en/products/kidney-injurypanel-3-human-kit-k15189d/ accessed 08 January 2018) containing seven biomarkers, component 2 of a principal component analysis containing B2M, cystatin C, NGAL and osteopontin predicted incident impaired eGFR [69]. Recently, of eight candidate biomarkers studied after adjustment for clinical predictors, apolipoprotein A4 (ApoA4), CD5 antigenlike (CD5L), and complement $\mathrm{Clq}$ subcomponent subunit $\mathrm{B}$ (C1QB) independently predicted rapid decline in eGFR in 345 people with type 2 diabetes. A notable feature of this study was the adjustment for extensive clinical covariates [70].

Thus, there is some, but not complete, overlap in the explored and selected biomarkers in these panel studies so that further optimisation of a panel of the best reported biomarkers could be considered, especially if it focused on including biomarkers with low correlation with each other. It is also the case that all of the studies, including our own, are too small and there is a need for a large-scale collaboration to increase power, quantify prediction and to demonstrate generalisability [25].

\section{Discovery 'omic' approaches}

Apart from candidate biomarkers on multiplexed panels, global discovery or 'hypothesis-free' approaches measuring large 
sets of lipids, metabolites and amino acids, peptides and proteins are increasingly used [71]. The assay methods have most commonly used mass spectrometry-based approaches, but other proteomic methods are now also used [72, 73]. Here we describe some of the main 'omic' studies, focusing on whether associations are prospective and whether they have adjusted for baseline eGFR and other relevant covariates.

CKD273 This mass spectrometry-based method combines data on 273 urinary peptides into a score that has high accuracy in the cross-sectional classification of eGFR status [74] and has been developed as a commercial test by Mosaique Diagnostics (http://mosaiques-diagnostics.de/mosaiques-diagnostics/, accessed 18 October 2017). Most (74\%) of the peptides are collagen fragments, with polymeric-immunoglobulin receptor, uromodulin (Tamm-Horsfall protein), clusterin, CD99 antigen, albumin, $\mathrm{B} 2 \mathrm{M}, \alpha 1$-antitrypsin and others comprising the remainder. The collagens, polymeric-immunoglobulin receptor, clusterin, CD99 antigen and uromodulin were lower with worse renal function, whereas the others were higher.

CKD273 was cross-sectionally associated with having albuminuria or/and eGFR $<45 \mathrm{ml} \mathrm{min}^{-1} 1.73 \mathrm{~m}^{-2}$ in individuals with type 2 diabetes [75]. In a small study $(n=35)$ of people with type 1 and type 2 diabetes the CKD273 score improved the $\mathrm{C}$ statistic for progression to albuminuria to 0.93 compared with 0.67 when using AER, but these data were not fully adjusted for baseline eGFR [76]. In 2672 participants from nine different cohorts, $76.3 \%$ with diabetes, CKD273 predicted rapid progression of eGFR better than AER [77]. In a nested case-control analysis, Roscioni et al reported a significant but smaller increase in $\mathrm{C}$ statistic for albuminuria incidence that was robust to adjustment for eGFR [78]. The most convincing data to date on the utility of CKD273 come from a subset of 737 samples obtained at baseline in the Diabetic Retinopathy Candesartan Trials (DIRECT)-Protect 2. The CKD273 score was strongly associated with incident microalbuminuria independently of baseline AER, eGFR and other variables. In this study, higher baseline eGFR was associated with incident microalbuminuria, an unusual finding, and CKD273 did not show the expected cross-sectional association with baseline eGFR [79]. Higher CKD273 score at baseline was associated with a larger reduction in ACR in the spironolactone group vs placebo ( $p=0.026$ for interaction) [80]. However, after adjustment for baseline ACR, the interaction between treatment and CKD273 was not statistically significant $(p=0.12)$. The concept that CKD273 will be useful in determining risk of disease progression and may also stratify treatment response to spironolactone is being more definitively tested in the ongoing Proteomic Prediction and Renin Angiotensin Aldosterone System Inhibition Prevention Of Early Diabetic nephRopathy In TYpe 2 Diabetic Patients With Normoalbuminuria (PRIORITY) trial, of 3280 participants with type 2 diabetes [81].
Other proteomics A nested case-control plasma proteomics study yielded kininogen and kininogen fragments as predictors of renal function decline. No adjustment was made for baseline eGFR but stratum matching was used [82]. Using a mass spectrometry approach on 252 urine peptides followed by ELISA validation in a nested case-control design, a panel including Tamm-Horsfall protein (also known as uromodulin), progranulin, clusterin and $\alpha-1$ acid glycoprotein improved prediction of early decline in eGFR in a cohort of 465 adults with type 1 diabetes, but no adjustment was made for baseline eGFR [83]. In another urinary proteomics study with a very small initial discovery step and then single biomarker validation in 204 participants, haptoglobin emerged to be the best predictor of early renal functional decline but no adjustment for baseline eGFR was made [84].

Metabolomics Several studies have also assessed the potential of metabolomics in the context of DKD. A recent systematic review [85] considered 12 studies (although all included control groups, most were cross-sectional), where a metabolomics-based approach was applied to identify potential biomarkers of DKD. The main metabolites were products of lipid metabolism (such as esterified and nonesterified fatty acids, carnitines, phospholipids), branchchain amino acid and aromatic amino acid metabolism, carnitine and tryptophan metabolism, nucleotide metabolism (purine, pyrimidine), the tricarboxylic acid cycle or uraemic solutes. The meta-analysis highlighted differences in the results from studies included and this might be related to differences in study population, sample selection, analytical platform.

In the SUMMIT study we used mass spectrometry to measure low-molecular-weight metabolites, peptide and proteins (144 in all) as well as 63 proteins by ELISA and Luminex in a prospective design. Adjusted for extensive covariates, the arginine methylated derivatives of protein turnover ADMA and SDMA, and more strongly their ratio, were independently predictive of rapid progression of eGFR. This ratio, along with metabolites uracil, $\alpha 1$-antitrypsin and C-16 acylcarnitine, were included in the final panel of seven biomarkers [25].

In summary, there are too many global discovery studies in which prediction has not been properly assessed on top of available clinical data, such that replication of findings with proper adjustments is warranted.

Genetic biomarkers Detailed reviews of the literature on genetic biomarkers of DKD have been recently published and are not the focus of this review [86]. In brief, a review of genetic discovery for DKD concluded that "the search for specific variants that confer predisposition to DKD has been relatively unrewarding" [86]. The effect sizes of the reported loci are very small in type 1 [87] and type 2 diabetes [88]. While international meta-analysis of data from the SUMMIT and other consortia are underway, given the effect sizes, it seems very 
unlikely that genetic risk scores for DKD will contribute usefully as biomarkers for use in the clinical prediction of DKD, even if they may reveal useful insights into pathogenesis.

MicroRNAs (miRNAs) MiRNAs are small non-coding RNA, that block protein translation and can induce messenger RNA degradation, thereby acting as regulators of gene expression [89]. Several studies have assessed urinary and serum miRNA in participants with type 1 and type 2 diabetes in relation to different DKD stages [90-97]. These studies are mostly very small [95] and most have reported simply cross-sectional associations of urinary miRNAs with albuminuria status [91, 93-96]. Three studies have used a nested case-control within prospective cohort design, one of which was in pooled samples [90, 92, 97]. However, there is no overlap in the specific miRNAs being reported as being relevant to DKD. Taken altogether there is not convincing evidence as yet for a clinically useful role for miRNAs in the prediction of DKD progression.

\section{Are any novel biomarkers actually being used yet?}

In reality, despite all the attempts to develop novel prognostic biomarkers, few current trials use biomarkers other than albuminuria or eGFR as stratification variables or entry criteria. An exception is the PRIORITY trial [81], in which the CKD273 panel is being used to risk stratify people into a spironolactone vs placebo arm.

Biomarkers as surrogates of drug response is not the focus of this review but we note that there are also few trials using surrogate biomarkers as endpoints. One ongoing trial is using urinary proteomic panels as a surrogate outcome measure [98]. Another study includes urinary NGAL and KIM-1 as secondary outcome measures [99], and another is using $N$-acyl- $\beta$-D-glucosidase, B2M and cystatin C [100]. The SYSKID consortium have argued that past trials have shown that albuminuria/eGFR are insufficient to predict the individual's response to renoprotective treatments in DKD, and that biomarkers more closely representing molecular mechanisms involved in disease progression and being targeted by therapies are needed [64]. Recently, Pena et al found that urinary metabolites previously shown to be at lower levels in those with DKD than without, decreased in the placebo arm of a trial but remained stable in the arm treated with the endothelin A receptor blocker atrasentan over a short, 12 week trial [101]. Further such studies of changes in biomarkers over time and in response to treatment are needed.

\section{Future perspectives}

In summary, despite the large number of reports in the literature, at present there are few validated biomarkers that have been clearly shown to substantially increase prediction of DKD-related phenotypes beyond known predictors. Few studies have attempted to estimate the marginal improvement in prediction beyond historical eGFR readings that can be expressed as the within-person slope or weighted average past eGFR, as we did in the SUMMIT study [25]. This is an important omission given the increasing availability of electronic healthcare records and potential for applying algorithms to such longitudinal clinical data more easily than measuring biomarkers. Even where some consistency in findings is observed, the extent of publication bias is unknown. Most importantly, biomarkers other than ACR and eGFR are not being routinely used to risk stratify individuals into trials or in clinical practice, despite considerable research investment into DKD biomarkers in recent years.

Large discovery panels have the potential to yield novel biomarkers, but progress has been hampered by small sample sizes, inadequate data analysis approaches (including failure to test the marginal increase beyond established risk factors) and lack of samples for replication. Futhermore, discovery approaches that yield panels of biomarkers measured on different platforms do not lend themselves to an easily implemented single panel in the clinical setting.

If this field is to be advanced, there is a need for a concerted effort to (1) generate and share data on the correlation between existing candidate biomarkers and biomarkers generated from available discovery platforms; (2) generate replication and validation sample and data sets that allow the best panel from available data to be defined; (3) harness the predictive information that exists in clinical records in the era of electronic health record data. Future discoveries should then be evaluated for their marginal prediction on top of clinical data and validated biomarkers.

Duality of interest HMC's institution has a patent co-filed for some of the biomarkers mentioned in this article.

Contribution statement Both authors were responsible for drafting the article and revising it critically for important intellectual content. Both authors approved the version to be published.

Open Access This article is distributed under the terms of the Creative Commons Attribution 4.0 International License (http:// creativecommons.org/licenses/by/4.0/), which permits unrestricted use, distribution, and reproduction in any medium, provided you give appropriate credit to the original author(s) and the source, provide a link to the Creative Commons license, and indicate if changes were made.

\section{References}

1. Livingstone SJ, Levin D, Looker HC et al (2015) Estimated life expectancy in a Scottish cohort with type 1 diabetes, 2008-2010. JAMA 313:37-44

2. Livingstone SJ, Looker HC, Hothersall EJ et al (2012) Risk of cardiovascular disease and total mortality in adults with type 1 diabetes: Scottish registry linkage study. PLoS Med 9:e1001321 
3. Chan GCW, Tang SCW (2016) Diabetic nephropathy: landmark clinical trials and tribulations. Nephrol Dial Transplant 31:359-368

4. Jones RH, Hayakawa H, Mackay JD, Parsons V, Watkins PJ (1979) Progression of diabetic nephropathy. Lancet 1:1105-1106

5. Michels WM, Grootendorst DC, Verduijn M, Elliott EG, Dekker FW, Krediet RT (2010) Performance of the Cockcroft-Gault, MDRD, and new CKD-EPI formulas in relation to GFR, age, and body size. Clin J Am Soc Nephrol 5:1003-1009

6. Stevens LA, Coresh J, Schmid CH et al (2008) Estimating GFR using serum cystatin $\mathrm{C}$ alone and in combination with serum creatinine: a pooled analysis of 3,418 individuals with CKD. Am J Kidney Dis 51:395-406

7. Barr EL, Maple-Brown LJ, Barzi F et al (2017) Comparison of creatinine and cystatin $\mathrm{C}$ based $\mathrm{eGFR}$ in the estimation of glomerular filtration rate in indigenous Australians: the eGFR Study. Clin Biochem 50:301-308

8. Menon V, Shlipak MG, Wang X et al (2007) Cystatin C as a risk factor for outcomes in chronic kidney disease. Ann Intern Med 147:19-27

9. Krolewski AS, Warram JH, Forsblom C et al (2012) Serum concentration of cystatin $\mathrm{C}$ and risk of end-stage renal disease in diabetes. Diabetes Care 35:2311-2316

10. Stevens LA, Schmid CH, Greene T et al (2009) Factors other than glomerular filtration rate affect serum cystatin $\mathrm{C}$ levels. Kidney Int 75:652-660

11. Macisaac RJ, Jerums G (2011) Diabetic kidney disease with and without albuminuria. Curr Opin Nephrol Hypertens 20:246-257

12. Retnakaran R, Cull CA, Thorne KI, Adler AI, Holman RR (2006) Risk factors for renal dysfunction in type 2 diabetes: U.K. Prospective Diabetes Study 74. Diabetes 55:1832-1839

13. Ekinci EI, Jerums G, Skene A et al (2013) Renal structure in normoalbuminuric and albuminuric patients with type 2 diabetes and impaired renal function. Diabetes Care 36:3620-3626

14. Krolewski AS (2015) Progressive renal decline: the new paradigm of diabetic nephropathy in type 1 diabetes. Diabetes Care 38:954 962

15. Radcliffe NJ, Seah J-M, Clarke M, MacIsaac RJ, Jerums G, Ekinci EI (2017) Clinical predictive factors in diabetic kidney disease progression. J Diabetes Investig 8:6-18

16. Keane WF, Brenner BM, de Zeeuw D et al (2003) The risk of developing end-stage renal disease in patients with type 2 diabetes and nephropathy: the RENAAL study. Kidney Int 63:1499-1507

17. Elley CR, Robinson T, Moyes SA et al (2013) Derivation and validation of a renal risk score for people with type 2 diabetes. Diabetes Care 36:3113-3120

18. Jardine MJ, Hata J, Woodward M et al (2012) Prediction of kidney-related outcomes in patients with type 2 diabetes. Am J Kidney Dis 60:770-778

19. Rosolowsky ET, Skupien J, Smiles AM et al (2011) Risk for ESRD in type 1 diabetes remains high despite renoprotection. J Am Soc Nephrol 22:545-553

20. Skupien J, Warram JH, Smiles AM, Stanton RC, Krolewski AS (2016) Patterns of estimated glomerular filtration rate decline leading to end-stage renal disease in type 1 diabetes. Diabetes Care 39: 2262-2269

21. Skupien J, Warram JH, Smiles AM et al (2012) The early decline in renal function in patients with type 1 diabetes and proteinuria predicts the risk of end stage renal disease. Kidney Int 82:589-597

22. Forsblom C, Moran J, Harjutsalo V et al (2014) Added value of soluble tumor necrosis factor- $\alpha$ receptor 1 as a biomarker of ESRD risk in patients with type 1 diabetes. Diabetes Care 37: 2334-2342

23. Andrésdóttir G, Jensen ML, Carstensen B et al (2015) Improved prognosis of diabetic nephropathy in type 1 diabetes. Kidney Int $87: 417-426$
24. Vergouwe Y, Soedamah-Muthu SS, Zgibor J et al (2010) Progression to microalbuminuria in type 1 diabetes: development and validation of a prediction rule. Diabetologia 53:254-262

25. Looker HC, Colombo M, Hess S et al (2015) Biomarkers of rapid chronic kidney disease progression in type 2 diabetes. Kidney Int 88:888-896

26. Ichimura T, Bonventre JV, Bailly V et al (1998) Kidney injury molecule-1 (KIM-1), a putative epithelial cell adhesion molecule containing a novel immunoglobulin domain, is up-regulated in renal cells after injury. J Biol Chem 273:4135-4142

27. Mishra J, Ma Q, Prada A et al (2003) Identification of neutrophil gelatinase-associated lipocalin as a novel early urinary biomarker for ischemic renal injury. J Am Soc Nephrol 14:2534-2543

28. Pavkov ME, Weil EJ, Fufaa GD et al (2016) Tumor necrosis factor receptors 1 and 2 are associated with early glomerular lesions in type 2 diabetes. Kidney Int 89:226-234

29. Niewczas MA, Gohda T, Skupien J et al (2012) Circulating TNF receptors 1 and 2 predict ESRD in type 2 diabetes. J Am Soc Nephrol 23:507-515

30. Gohda T, Niewczas MA, Ficociello LH et al (2012) Circulating TNF receptors 1 and 2 predict stage 3 CKD in type 1 diabetes. J Am Soc Nephrol 23:516-524

31. Pavkov ME, Nelson RG, Knowler WC, Cheng Y, Krolewski AS, Niewczas MA (2015) Elevation of circulating TNF receptors 1 and 2 increases the risk of end-stage renal disease in American Indians with type 2 diabetes. Kidney Int 87:812-819

32. Yamanouchi M, Skupien J, Niewczas MA et al (2017) Improved clinical trial enrollment criterion to identify patients with diabetes at risk of end-stage renal disease. Kidney Int 92:258-266

33. Lopes-Virella MF, Baker NL, Hunt KJ, Cleary PA, Klein R, Virella G (2013) Baseline markers of inflammation are associated with progression to macroalbuminuria in type 1 diabetic subjects. Diabetes Care 36:2317-2323

34. Antonellis PJ, Kharitonenkov A, Adams AC (2014) Physiology and Endocrinology Symposium: FGF21: insights into mechanism of action from preclinical studies. J Anim Sci 92:407-413

35. Stein S, Bachmann A, Lossner U et al (2009) Serum levels of the adipokine FGF21 depend on renal function. Diabetes Care 32: 126-128

36. Han SH, Choi SH, Cho BJ et al (2010) Serum fibroblast growth factor-21 concentration is associated with residual renal function and insulin resistance in end-stage renal disease patients receiving long-term peritoneal dialysis. Metabolism 59:1656-1662

37. Jian W-X, Peng W-H, Jin J et al (2012) Association between serum fibroblast growth factor 21 and diabetic nephropathy. Metabolism 61:853-859

38. Fon Tacer K, Bookout AL, Ding X et al (2010) Research resource: comprehensive expression atlas of the fibroblast growth factor system in adult mouse. Mol Endocrinol 24:2050-2064

39. Kim HW, Lee JE, Cha JJ et al (2013) Fibroblast growth factor 21 improves insulin resistance and ameliorates renal injury in $\mathrm{db} / \mathrm{db}$ mice. Endocrinology 154:3366-3376

40. Har RLH, Reich HN, Scholey JW et al (2014) The urinary cytokine/chemokine signature of renal hyperfiltration in adolescents with type 1 diabetes. PLoS One 9:e111131

41. Cherney DZI, Scholey JW, Daneman D et al (2012) Urinary markers of renal inflammation in adolescents with type 1 diabetes mellitus and normoalbuminuria. Diabet Med 29:1297-1302

42. Hui E, Yeung C-Y, Lee PCH et al (2014) Elevated circulating pigment epithelium-derived factor predicts the progression of diabetic nephropathy in patients with type 2 diabetes. J Clin Endocrinol Metab 99:E2169-E2177

43. Bidadkosh A, Lambooy SPH, Heerspink HJ et al (2017) Predictive properties of biomarkers GDF-15, NTproBNP, and hs-TnT for morbidity and mortality in patients with type 2 diabetes with nephropathy. Diabetes Care 40:784-792 
44. Velho G, El Boustany R, Lefèvre G et al (2016) Plasma copeptin, kidney outcomes, ischemic heart disease, and all-cause mortality in people with long-standing type 1 diabetes. Diabetes Care 39: 2288-2295

45. Velho G, Bouby N, Hadjadj S et al (2013) Plasma copeptin and renal outcomes in patients with type 2 diabetes and albuminuria. Diabetes Care 36:3639-3645

46. Boertien WE, Riphagen IJ, Drion I et al (2013) Copeptin, a surrogate marker for arginine vasopressin, is associated with declining glomerular filtration in patients with diabetes mellitus (ZODIAC33). Diabetologia 56:1680-1688

47. Pikkemaat M, Melander O, Bengtsson Boström K (2015) Association between copeptin and declining glomerular filtration rate in people with newly diagnosed diabetes. The Skaraborg Diabetes Register. J Diabetes Complicat 29:1062-1065

48. Nielsen SE, Reinhard H, Zdunek D et al (2012) Tubular markers are associated with decline in kidney function in proteinuric type 2 diabetic patients. Diabetes Res Clin Pract 97:71-76

49. Fu W-J, Li B-L, Wang S-B et al (2012) Changes of the tubular markers in type 2 diabetes mellitus with glomerular hyperfiltration. Diabetes Res Clin Pract 95:105-109

50. Garg V, Kumar M, Mahapatra HS, Chitkara A, Gadpayle AK, Sekhar V (2015) Novel urinary biomarkers in pre-diabetic nephropathy. Clin Exp Nephrol 19:895-900

51. Kamijo-Ikemori A, Sugaya T, Yasuda T et al (2011) Clinical significance of urinary liver-type fatty acid-binding protein in diabetic nephropathy of type 2 diabetic patients. Diabetes Care 34:691696

52. Viswanathan V, Sivakumar S, Sekar V, Umapathy D, Kumpatla S (2015) Clinical significance of urinary liver-type fatty acid binding protein at various stages of nephropathy. Indian J Nephrol 25:269 273

53. Araki S, Haneda M, Koya D et al (2013) Predictive effects of urinary liver-type fatty acid-binding protein for deteriorating renal function and incidence of cardiovascular disease in type 2 diabetic patients without advanced nephropathy. Diabetes Care 36:12481253

54. Yin C, Wang N (2016) Kidney injury molecule-1 in kidney disease. Ren Fail 38:1567-1573

55. Zhao X, Zhang Y, Li L et al (2011) Glomerular expression of kidney injury molecule-1 and podocytopenia in diabetic glomerulopathy. Am J Nephrol 34:268-280

56. Alter ML, Kretschmer A, Von Websky K et al (2012) Early urinary and plasma biomarkers for experimental diabetic nephropathy. Clin Lab 58:659-671

57. Waikar SS, Sabbisetti V, Arnlov J et al (2016) Relationship of proximal tubular injury to chronic kidney disease as assessed by urinary kidney injury molecule-1 in five cohort studies. Nephrol Dial Transplant 31:1460-1470

58. Sabbisetti VS, Waikar SS, Antoine DJ et al (2014) Blood kidney injury molecule- 1 is a biomarker of acute and chronic kidney injury and predicts progression to ESRD in type I diabetes. J Am Soc Nephrol 25:2177-2186

59. Nielsen SE, Andersen S, Zdunek D, Hess G, Parving H-H, Rossing P (2011) Tubular markers do not predict the decline in glomerular filtration rate in type 1 diabetic patients with overt nephropathy. Kidney Int 79:1113-1118

60. Conway BR, Manoharan D, Manoharan D et al (2012) Measuring urinary tubular biomarkers in type 2 diabetes does not add prognostic value beyond established risk factors. Kidney Int 82:812818

61. Vaidya VS, Niewczas MA, Ficociello LH et al (2011) Regression of microalbuminuria in type 1 diabetes is associated with lower levels of urinary tubular injury biomarkers, kidney injury molecule-1, and $N$-acetyl- $\beta$-D-glucosaminidase. Kidney Int 79:464 470
62. Panduru NM, Sandholm N, Forsblom C et al (2015) Kidney injury molecule-1 and the loss of kidney function in diabetic nephropathy: a likely causal link in patients with type 1 diabetes. Diabetes Care 38:1130-1137

63. Heinzel A, Muhlberger I, Fechete R, Mayer B, Perco P (2014) Functional molecular units for guiding biomarker panel design. Methods Mol Biol 1159:109-133

64. Pena MJ, Heinzel A, Heinze G et al (2015) A panel of novel biomarkers representing different disease pathways improves prediction of renal function decline in type 2 diabetes. PLoS One 10: e0120995

65. Heinzel A, Mühlberger I, Stelzer G et al (2015) Molecular disease presentation in diabetic nephropathy. Nephrol Dial Transplant 30(Suppl 4):iv17-iv25

66. Mayer G, Heerspink HJL, Aschauer C et al (2017) Systems biology-derived biomarkers to predict progression of renal function decline in type 2 diabetes. Diabetes Care 40:391-397

67. Agarwal R, Duffin KL, Laska DA, Voelker JR, Breyer MD, Mitchell PG (2014) A prospective study of multiple protein biomarkers to predict progression in diabetic chronic kidney disease. Nephrol Dial Transplant 29:2293-2302

68. Verhave JC, Bouchard J, Goupil R et al (2013) Clinical value of inflammatory urinary biomarkers in overt diabetic nephropathy: a prospective study. Diabetes Res Clin Pract 101:333-340

69. Bjornstad P, Pyle L, Cherney DZI et al (2017) Plasma biomarkers improve prediction of diabetic kidney disease in adults with type 1 diabetes over a 12-year follow-up: CACTI study. Nephrol Dial Transplant. https://doi.org/10.1093/ndt/gfx255

70. Peters KE, Davis WA, Ito J et al (2017) Identification of novel circulating biomarkers predicting rapid decline in renal function in type 2 diabetes: the Fremantle Diabetes Study Phase II. Diabetes Care 40:1548-1555

71. Pena MJ, Mischak H, Heerspink HJL (2016) Proteomics for prediction of disease progression and response to therapy in diabetic kidney disease. Diabetologia 59:1819-1831

72. Gold L, Ayers D, Bertino J et al (2010) Aptamer-based multiplexed proteomic technology for biomarker discovery. PLoS One 5:e15004

73. Carlsson AC, Ingelsson E, Sundstrom J et al (2017) Use of proteomics to investigate kidney function decline over 5 years. Clin J Am Soc Nephrol 12:1226-1235

74. Argiles A, Siwy J, Duranton F et al (2013) CKD273, a new proteomics classifier assessing CKD and its prognosis. PLoS One 8: e62837

75. Siwy J, Schanstra JP, Argiles A et al (2014) Multicentre prospective validation of a urinary peptidome-based classifier for the diagnosis of type 2 diabetic nephropathy. Nephrol Dial Transplant 29:1563-1570

76. Zürbig P, Jerums G, Hovind P et al (2012) Urinary proteomics for early diagnosis in diabetic nephropathy. Diabetes 61:3304-3313

77. Pontillo C, Jacobs L, Staessen JA et al (2017) A urinary proteomebased classifier for the early detection of decline in glomerular filtration. Nephrol Dial Transplant 32:1510-1516

78. Roscioni SS, de Zeeuw D, Hellemons ME et al (2013) A urinary peptide biomarker set predicts worsening of albuminuria in type 2 diabetes mellitus. Diabetologia 56:259-267

79. Lindhardt M, Persson F, Zürbig P et al (2017) Urinary proteomics predict onset of microalbuminuria in normoalbuminuric type 2 diabetic patients, a sub-study of the DIRECT-Protect 2 study. Nephrol Dial Transplant 32:1866-1873

80. Lindhardt M, Persson F, Oxlund C et al (2018) Predicting albuminuria response to spironolactone treatment with urinary proteomics in patients with type 2 diabetes and hypertension. Nephrol Dial Transplant. 33:296-303

81. Lindhardt M, Persson F, Currie G et al (2016) Proteomic prediction and renin angiotensin aldosterone system inhibition 
prevention of early diabetic nephropathy in type 2 diabetic patients with normoalbuminuria (PRIORITY): essential study design and rationale of a randomised clinical multicentre trial. BMJ Open 6: e010310

82. Merchant ML, Niewczas MA, Ficociello LH et al (2013) Plasma kininogen and kininogen fragments are biomarkers of progressive renal decline in type 1 diabetes. Kidney Int 83:1177-1184

83. Schlatzer D, Maahs DM, Chance MR et al (2012) Novel urinary protein biomarkers predicting the development of microalbuminuria and renal function decline in type 1 diabetes. Diabetes Care 35:549-555

84. Bhensdadia NM, Hunt KJ, Lopes-Virella MF et al (2013) Urine haptoglobin levels predict early renal functional decline in patients with type 2 diabetes. Kidney Int 83:1136-1143

85. Zhang Y, Zhang S, Wang G (2015) Metabolomic biomarkers in diabetic kidney diseases - a systematic review. J Diabetes Complicat 29:1345-1351

86. Ahlqvist E, van Zuydam NR, Groop LC, McCarthy MI (2015) The genetics of diabetic complications. Nat Rev Nephrol 11:277287

87. Sandholm N, Salem RM, McKnight AJ et al (2012) New susceptibility loci associated with kidney disease in type 1 diabetes. PLoS Genet 8:e1002921

88. Teumer A, Tin A, Sorice R et al (2016) Genome-wide association studies identify genetic loci associated with albuminuria in diabetes. Diabetes 65:803-817

89. Simpson K, Wonnacott A, Fraser DJ, Bowen T (2016) MicroRNAs in diabetic nephropathy: from biomarkers to therapy. Curr Diab Rep 16:35

90. Argyropoulos C, Wang K, Bernardo J et al (2015) Urinary MicroRNA profiling predicts the development of microalbuminuria in patients with type 1 diabetes. J Clin Med 4: 1498-1517

91. Argyropoulos C, Wang K, McClarty S et al (2013) Urinary microRNA profiling in the nephropathy of type 1 diabetes. PLoS One 8:e54662

92. Pezzolesi MG, Satake E, McDonnell KP, Major M, Smiles AM, Krolewski AS (2015) Circulating TGF- $\beta 1$-regulated miRNAs and the risk of rapid progression to ESRD in type 1 diabetes. Diabetes 64:3285-3293

93. Peng $\mathrm{H}$, Zhong M, Zhao W et al (2013) Urinary miR-29 correlates with albuminuria and carotid intima-media thickness in type 2 diabetes patients. PLoS One 8:e82607

94. Zhou J, Peng R, Li T et al (2013) A potentially functional polymorphism in the regulatory region of let-7a-2 is associated with an increased risk for diabetic nephropathy. Gene 527:456-461

95. Delic D, Eisele C, Schmid R et al (2016) Urinary exosomal miRNA signature in type II diabetic nephropathy patients. PLoS One 11:e0150154

96. Eissa S, Matboli M, Aboushahba R, Bekhet MM, Soliman Y (2016) Urinary exosomal microRNA panel unravels novel biomarkers for diagnosis of type 2 diabetic kidney disease. J Diabetes Complicat 30:1585-1592

97. Barutta F, Bruno G, Matullo G et al (2017) MicroRNA-126 and micro-/macrovascular complications of type 1 diabetes in the EURODIAB Prospective Complications Study. Acta Diabetol 54:133-139

98. Effects of dapagliflozin treatment on urinary proteomic patterns in patients with type 2 diabetes (DapKid). https://clinicaltrials.gov/ ct2/show/NCT02914691. Accessed 17 Oct 2017

99. Renoprotective effects of dapagliflozin in type 2 diabetes (RED) https://clinicaltrials.gov/ct2/show/NCT02682563. Accessed 17 Oct 2017

100. Ivabradine to treat microalbuminuria in patients with type 2 diabetes and coronary heart disease $(\mathrm{BENCH}) \mathrm{https} / /$ clinicaltrials. gov/ct2/show/NCT03105219. Accessed 17 Oct 2017
101. Pena MJ, de Zeeuw D, Andress D et al (2017) The effects of atrasentan on urinary metabolites in patients with type 2 diabetes and nephropathy. Diabetes Obes Metab 19:749-753

102. Burns KD, Lytvyn Y, Mahmud FH et al (2017) The relationship between urinary renin-angiotensin system markers, renal function, and blood pressure in adolescents with type 1 diabetes. Am J Physiol Renal Physiol 312:F335-F342

103. Carlsson AC, Östgren CJ, Länne T, Larsson A, Nystrom FH, Ärnlöv J (2016) The association between endostatin and kidney disease and mortality in patients with type 2 diabetes. Diabetes Metab 42:351-357

104. Dieter BP, McPherson SM, Afkarian M et al (2016) Serum amyloid a and risk of death and end-stage renal disease in diabetic kidney disease. J Diabetes Complicat 30:1467-1472

105. Wang Y, Li Y-M, Zhang S, Zhao J-Y, Liu C-Y (2016) Adipokine zinc-alpha-2-glycoprotein as a novel urinary biomarker presents earlier than microalbuminuria in diabetic nephropathy. J Int Med Res 44:278-286

106. Fufaa GD, Weil EJ, Nelson RG et al (2015) Association of urinary KIM-1, L-FABP, NAG and NGAL with incident end-stage renal disease and mortality in American Indians with type 2 diabetes mellitus. Diabetologia 58:188-198

107. Bouvet BR, Paparella CV, Arriaga SMM, Monje AL, Amarilla AM, Almará AM (2014) Evaluation of urinary N-acetyl-beta-Dglucosaminidase as a marker of early renal damage in patients with type 2 diabetes mellitus. Arq Bras Endocrinol Metabol 58:798801

108. Petrica L, Vlad A, Gluhovschi G et al (2014) Proximal tubule dysfunction is associated with podocyte damage biomarkers nephrin and vascular endothelial growth factor in type 2 diabetes mellitus patients: a cross-sectional study. PLoS One 9:e112538

109. Wu C, Wang Q, Lv C et al (2014) The changes of serum sKlotho and NGAL levels and their correlation in type 2 diabetes mellitus patients with different stages of urinary albumin. Diabetes Res Clin Pract 106:343-350

110. do Nascimento JF, Canani LH, Gerchman F et al (2013) Messenger RNA levels of podocyte-associated proteins in subjects with different degrees of glucose tolerance with or without nephropathy. BMC Nephrol 14:214

111. Panduru NM, Forsblom C, Saraheimo M et al (2013) Urinary liver-type fatty acid-binding protein and progression of diabetic nephropathy in type 1 diabetes. Diabetes Care 36:2077-2083

112. Lee JE, Gohda T, Walker WH et al (2013) Risk of ESRD and all cause mortality in type 2 diabetes according to circulating levels of FGF-23 and TNFR1. PLoS One 8:e58007

113. Jim B, Ghanta M, Qipo A et al (2012) Dysregulated nephrin in diabetic nephropathy of type 2 diabetes: a cross sectional study. PLoS One 7:e36041

114. Coca SG, Nadkarni GN, Huang Y et al (2017) Plasma biomarkers and kidney function decline in early and established diabetic kidney disease. J Am Soc Nephrol 28:2786-2793

115. Saulnier P-J, Gand E, Velho G et al (2017) Association of circulating biomarkers (adrenomedullin, TNFR1, and NT-proBNP) with renal function decline in patients with type 2 diabetes: a French prospective cohort. Diabetes Care 40:367-374

116. Pena MJ, Jankowski J, Heinze G et al (2015) Plasma proteomics classifiers improve risk prediction for renal disease in patients with hypertension or type 2 diabetes. J Hypertens 33:2123-2132

117. Foster MC, Inker LA, Hsu C-Y et al (2015) Filtration markers as predictors of ESRD and mortality in Southwestern American Indians with type 2 diabetes. Am J Kidney Dis 66:75-83

118. Titan SM, Vieira JM, Dominguez WV et al (2012) Urinary MCP-1 and RBP: independent predictors of renal outcome in macroalbuminuric diabetic nephropathy. J Diabetes Complicat $26: 546-553$ 
119. Niewczas MA, Mathew AV, Croall S et al (2017) Circulating modified metabolites and a risk of ESRD in patients with type 1 diabetes and chronic kidney disease. Diabetes Care 40:383-390

120. Klein RL, Hammad SM, Baker NL et al (2014) Decreased plasma levels of select very long chain ceramide species are associated with the development of nephropathy in type 1 diabetes. Metabolism 63:1287-1295

121. Pena MJ, Lambers Heerspink HJ, Hellemons ME et al (2014) Urine and plasma metabolites predict the development of diabetic nephropathy in individuals with type 2 diabetes mellitus. Diabet Med 31:1138-1147

122. Niewczas MA, Sirich TL, Mathew AV et al (2014) Uremic solutes and risk of end-stage renal disease in type 2 diabetes: metabolomic study. Kidney Int 85:1214-1224

123. Sharma K, Karl B, Mathew AV et al (2013) Metabolomics reveals signature of mitochondrial dysfunction in diabetic kidney disease. J Am Soc Nephrol 24:1901-1912
124. Hirayama A, Nakashima E, Sugimoto M et al (2012) Metabolic profiling reveals new serum biomarkers for differentiating diabetic nephropathy. Anal Bioanal Chem 404:3101-3109

125. van der Kloet FM, Tempels FWA, Ismail N et al (2012) Discovery of early-stage biomarkers for diabetic kidney disease using msbased metabolomics (FinnDiane study). Metabolomics 8:109-119

126. Ng DPK, Salim A, Liu Y et al (2012) A metabolomic study of low estimated GFR in non-proteinuric type 2 diabetes mellitus. Diabetologia 55:499-508

127. Han L-D, Xia J-F, Liang Q-L et al (2011) Plasma esterified and non-esterified fatty acids metabolic profiling using gas chromatography-mass spectrometry and its application in the study of diabetic mellitus and diabetic nephropathy. Anal Chim Acta 689:85-91 